Annals of Glaciology $3 \quad 1982$

(c) International Glaciological Society

\title{
PHYSICAL AND STRUCTURAL CHARACTERISTICS OF
}

\section{ANTARCTIC SEA ICE}

by

\author{
A. J. Gow, S. F. Ackley, W. F. Weeks and J. W. Govoni
}

(U. S. Army Cold Regions Research and Engineering Laboratory, Hanover, New Hampshire 03755, U.S.A.)

\section{ABSTRACT}

Observations during February and March 1980 of structures in 66 separate floes in Weddell Sea pack ice show widespread occurrence of frazil ice in amounts not previously reported in sea ice of comparable age and thickness in the Arctic. It is estimated that as much as $50 \%$ of the total ice production in the Weddell Sea is generated as frazil. Average floe salinities also appear higher than those of their Arctic counterparts. Comparative studies of fast ice at 28 locations in McMurdo Sound show this ice to be composed almost entirely of congelation ice that exhibits crystalline textures and orientations that are similar to those observed in Arctic fast ice. However, average fast-ice salinities in McMurdo Sound are higher than those reported for Arctic fast ice of comparable age and thickness.

\section{INTRODUCTION}

Recent studies of the factors bearing on the dynamics and thermodynamics of sea ice in the Antarctic have included investigations of the physical and structural properties of sea ice in the Weddel1 Sea and McMurdo Sound. The overall scope of these investigations, including some results, is reported in Ack ley (1979 and 1981). Ackley and others (1980) and Gow and others (1981). In this paper we describe, in greater detail, the salinity and structural characteristics of ice floes in the Weddell Sea and of fast ice in McMurdo Sound. Our observations show that these properties can differ appreciably from those reported for sea ice of comparable age, thermal history, and thickness in the Arctic.

WEDDELL SEA STUDIES

Weddel1 Sea pack ice was investigated in February and March 1980, using helicopters aboard USCGC Polar Sea to obtain samples from drifting floes located along a north-south transect that covered approximately 600 nautical miles from $64^{\circ} \mathrm{S}$ to $74^{\circ}$ latitude at roughly $40^{\circ} \mathrm{W}$ longitude (Fig.1). Samples were obtained with a coring auger from 66 individual ice floes, including 13 multi-year floes. A total of $138 \mathrm{~m}$ of core was retrieved. Cores were split lengthwise on board ship where salinity measurements and some preliminary examinations of the crystalline structure of the ice were made. The remaining halfcores together with some whole cores were returned to the US Army Cold Regions Research and Engineering Laboratory (USACRREL) for further analysis.

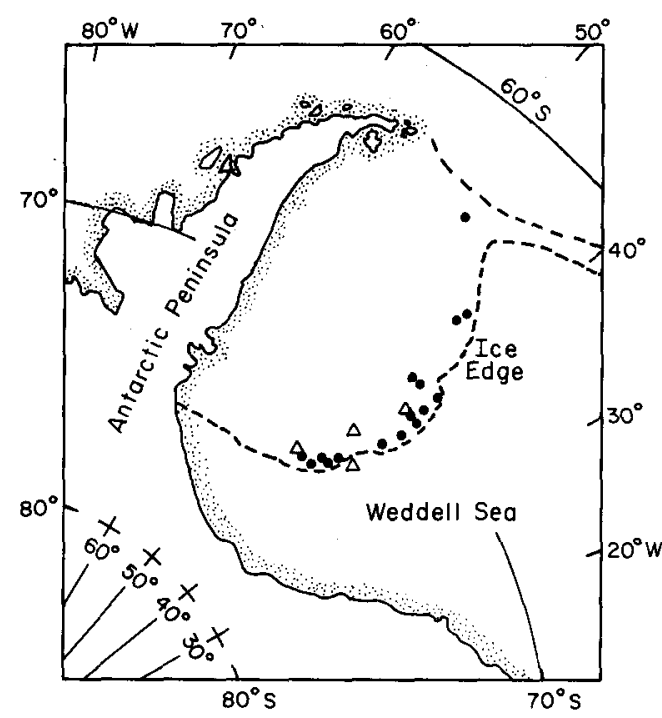

Fig.1. Locations of primary sea-ice sampling sites (circles) and data buoys (triangles) used for satellite monitoring of drift and deformation of the pack ice in the Weddell Sea.

\section{Internal structure of ice}

Preliminary studies aboard ship of the crystalline structure in horizontal thin sections of ice from 16 separate f1oes, ranging in thickness from 0.2 to $5 \mathrm{~m}$, revealed that Weddell Sea pack ice contained significant amounts of frazil ice, derived from smal1 crystals nucleated in the water column, as opposed to congelation ice, formed by freezing of sea-water directly to the bottom of the existing pack ice. Most of the thin sections were made at or close to natural core breaks prior to splitting the core. The suspicion that the core breaks might coincide with structural discontinuities, for example congelation ice/frazil ice transitions, was subsequentiy confirmed when vertical structure sections were examined in conjunction with horizontal thin sections at USACRREL. Complete vertical sectioning of cores from 34 individual floes, including eight multi-year, 23 first-year, and three of undetermined age, has shown that many floes contain in excess of $50 \%$ frazil ice, and some may consist of as much as $90 \%$ frazil 


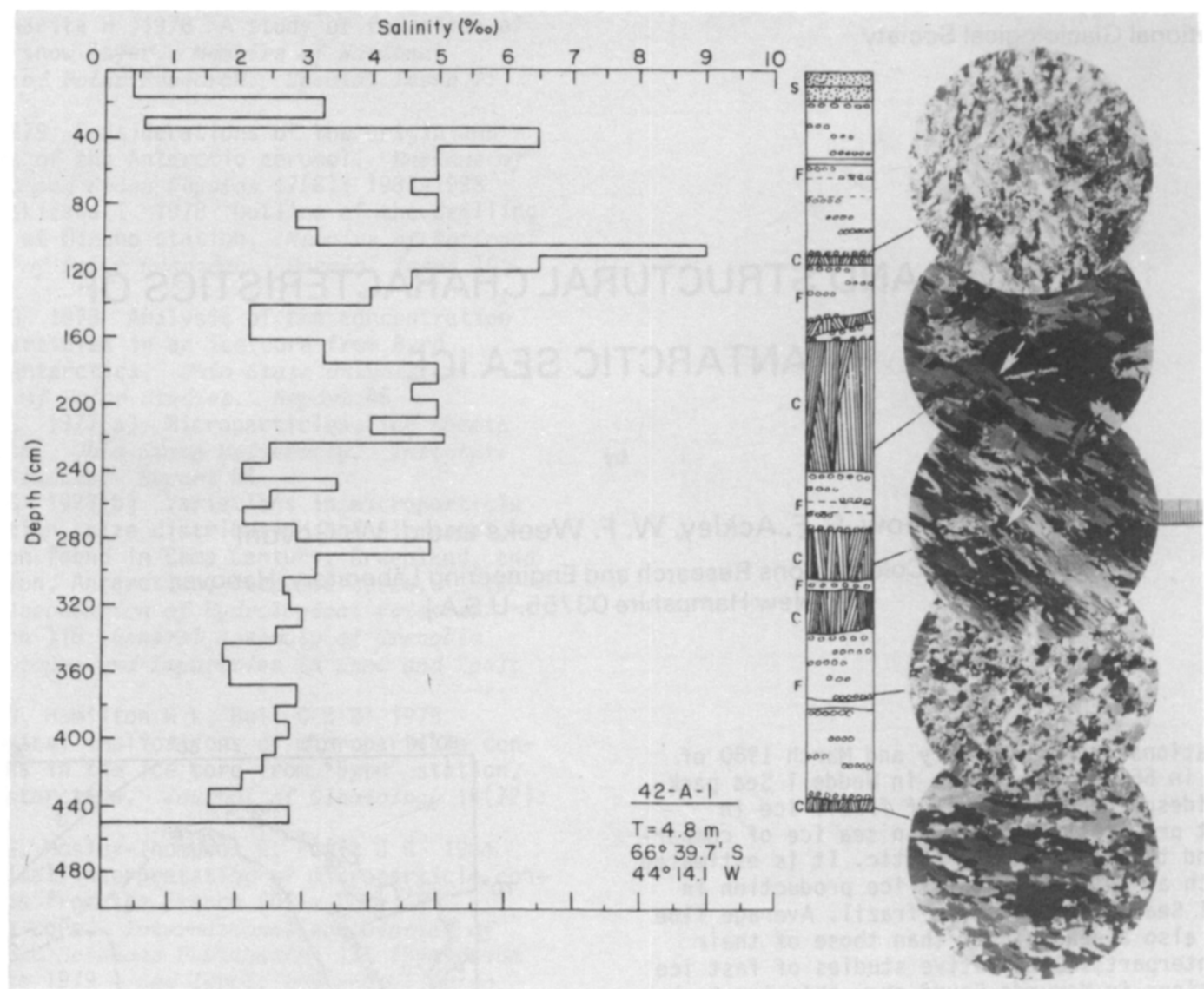

Fig.2. Salinity profile, vertical-structure section, and selected horizontal thinsection photographs of crystal structure of sea ice at site 42-A-1. The symbols $S$, $F$, and $C$ located on the left side of the vertical structure section denote snow ice, frazil ice, and congelation ice, respectively. The same notation applies also to the other three sections in Figures 3 to 5 . The smallest subdivision of the scale beside the horizontal thin-section photograph of ice from $2.93 \mathrm{~m}$ measures $1 \mathrm{~mm}$; al1 other sections in Figures 3 to 5 are also photographed at the same scale.

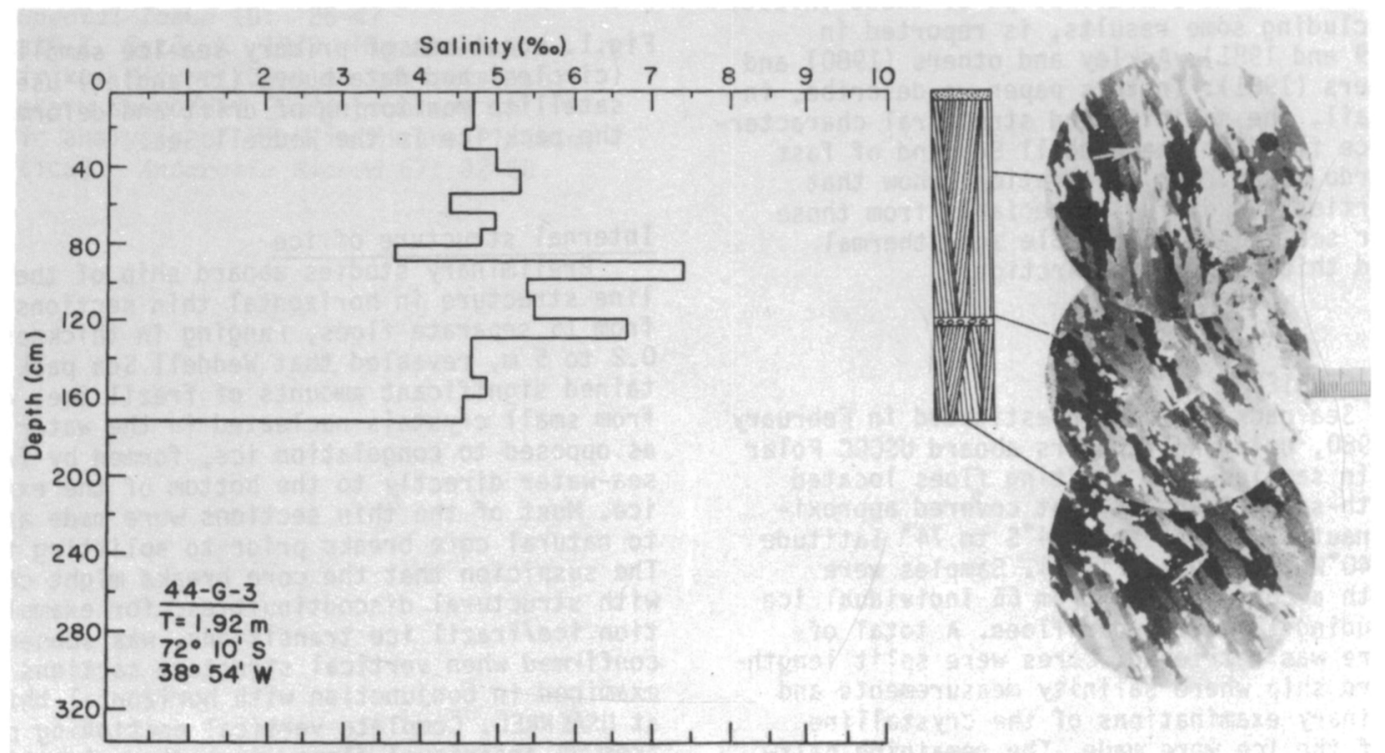

Fig.3. Salinity profile, vertical-structure section, and selected horizontal thin-section photographs of crystal structure from ice floe $43-A-2$. 


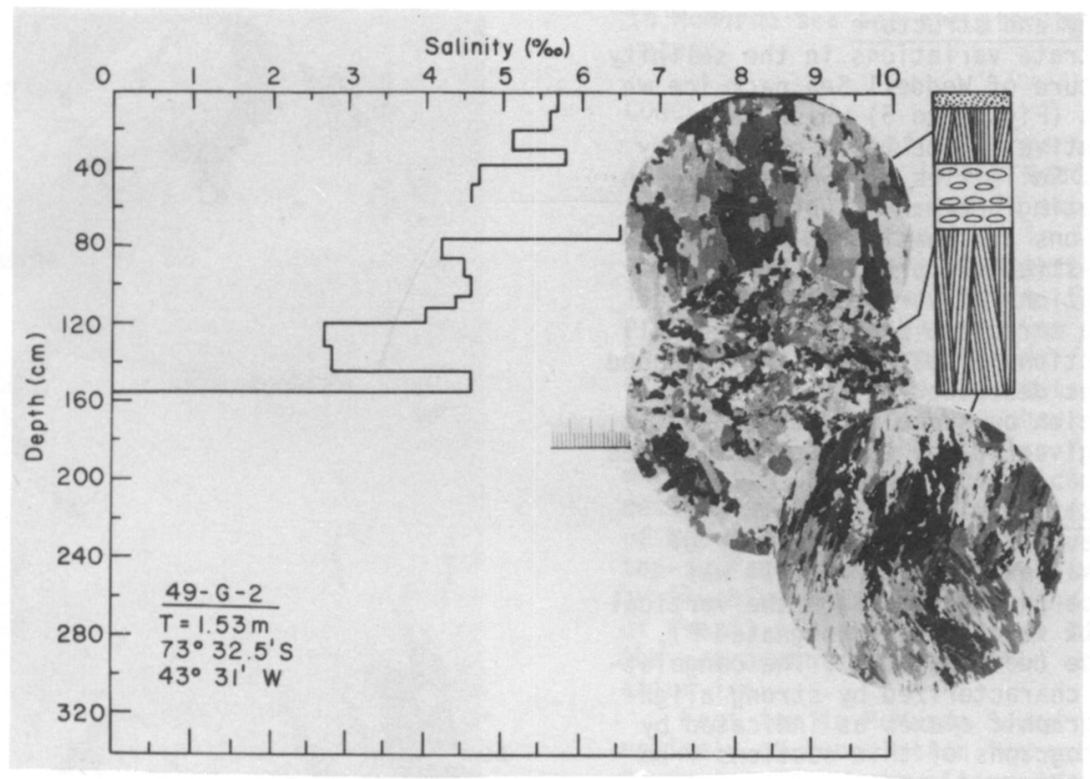

Fig.4. Salinity profile, vertical-structure section, and selected horizontal thin-section photographs of crystal structure from ice fl oe $44-\mathrm{G}-3$.

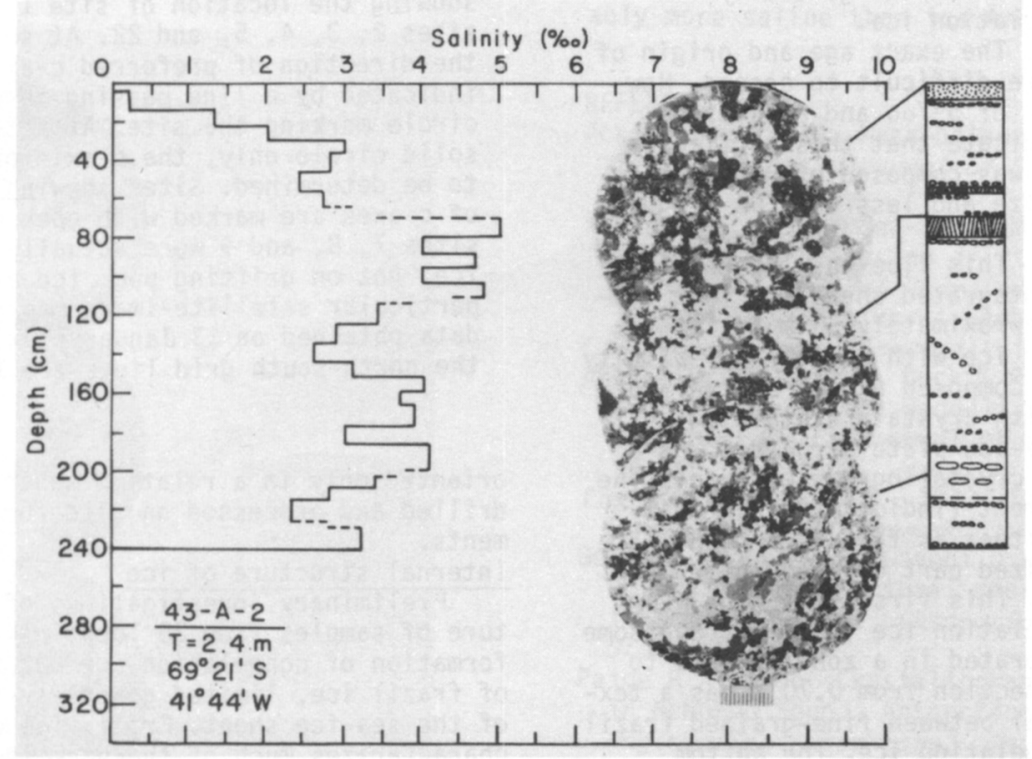

Fig.5. Salinity profile, vertical-structure section, and selected horizontal thin-section photographs of crystal structure from ice floe $49-\mathrm{G}-2$.

ice. This scale of frazil production in the Weddell Sea has led to exceptional ice-floe thickness, approaching $5 \mathrm{~m}$ of ice growth in a number of floes. This growth has occurred in $<2$ a, based on ice-drift measurements from data buoys (Ackley 1981). We suggest that much of this frazil is the result of brine convection induced by rapid freezing of seawater in leads and polynyas. If this formation of frazil is as widespread as our results indicate then the role of deformation, i.e. the opening and closing of leads and polynyas, may play a greater part in the formation of the Weddell Sea pack than similar processes do in the Arctic.

Salinity measurements

From the large number of salinities measured we find that Weddell Sea pack ice is appreciably more saline than Arctic ice of comparable age and thickness. For example, the average salinity of 33 first-year floes from the Weddel1 Sea measured $4.6 \%$ with values of around $3 \%$ oo that Cox and Weeks (1973) report for warm Arctic ice of comparable thickness. Similarly, measurements on nine multi-year floes from the Weddeil Sea yielded an average salinity of $3.7 \% \%$ which is significantly higher than a value of around $2 \%$ reported by COx and Weeks (1973) for floes of comparable age and thickness $(3$ to $5 \mathrm{~m})$ in the Arctic. In fact, floe salinities measured in late summer in the Weddell Sea are more comparable with Arctic winter ice. This situation probably arises as the result of two distinct processes. The first and perhaps major factor is the very low top surface summer melt observed in Weddell Sea pack ice (Ackley 1979) which allows the floes to retain brine that would otherwise be flushed out by downward percolating melt water, an important cause of brine loss in Arctic summer ice. A second factor which may lead to higher salinities initially is the process of frazilice formation which tends to entrap more sea-water into the sponge-like ice structure than occurs in the formation of congelation ice. 


\section{Floe profiles: salinity and structure}

In order to illustrate variations in the salinity and crystalline structure of Weddell sea pack ice we have chosen four floes (Figs.2 to 5) which we believe are representative of ice types observed by us in the Weddell Sea. Salinities were measured with a temperature-compensating Beckman Salubridge. Individua 1 determinations are considered accurate to $\pm 0.2 \%$. Vertical-structure profiles are based on light-table examinations of vertically sectioned cores. The crystalline structure photographs are all of horizontal thin sections prepared and photographed according to procedures described by Weeks and Gow $(1978,1980)$. Information on symbols used, scales, and related data are given in the captions to Figures 2 to 5 .

Floe $42-A-1$ (see Fig.2). This floe was of thick $(4.8 \mathrm{~m})$ multi-year ice with a maximum salinity of $90 \%$ and an average salinity of $3.5 \%$. It was composed of $4 \%$ snow ice (designated $S$ in the vertical structure profile), $61 \%$ frazil ice (designated $F$ ), and $35 \%$ congelation ice (designated C). The congelation ice component was characterized by strong alignment of the crystallographic c-axes as indicated by the arrows in the photographs of thin sections from $2.24 \mathrm{~m}$ and $2.93 \mathrm{~m}$. In this and other profiles presented here, the smaller size of crystals and the absence of brine lamellae-ice plate structure serve to distinguish frazil ice from the generally fibrously textured congelation ice.

Floe 43-A-2 (see Fig.3). The exact age and origin of this floe $2.4 \mathrm{~m}$ thick are difficult to assess. However, a maximum salinity of $5 \%$ and an average value of about $3 \% \% 0$ indicate that this particular floe was multi-year. It was composed of $90 \%$ frazil ice of variable grain size and less than $6 \%$ congelation ice.

Floe 44-G-3 (see Fig.4). This floe was located in a region of recently disintegrated sheet ice that produced floes measuring approximately $30 \mathrm{~m}$ in length. Identified as first-year ice with an average salinity of $5 \%$, this floe was composed a1most entirely of congelation ice $(95 \%)$ with crystals exhibiting welldeveloped brine lamellae-ice plate structure and a strong alignment of the crystallographic c-axes. The constancy of this alignment (indicated by arrows) suggests that it grew either as fast ice or in place in a relatively immobilized part of the winter pack. Floe 49-G-2 (see Fig.5). This first-year floe was composed mainly of congelation ice (72\%) but had some frazil ice (22\%) incorporated in a zone at 0.26 to $0.70 \mathrm{~m}$ depth. The thin section from $0.70 \mathrm{~m}$ has a texture that is transitional between fine-grained frazil and coarser-grained congelation ice. The bottom section comprised fibrously textured crystals, randomly aligned. The average salinity of the floe was $4.7 \%$.

\section{MCMURDO SOUND STUDIES}

Studies conducted in McMurdo Sound during october and November 1980 were restricted to fast ice that had formed since April 1980, following a major breakout of ice in February 1980. This break-out virtually eliminated all previously existing sea ice in McMurdo Sound, including several generations of multi-year ice. Only at one location, near Cape Chocolate on the western shore of McMurdo Sound, was multi-year ice observed and sampled. The location of this one sample of multi-year ice (site 18) and of all other samples obtained during this recent survey of sea ice in McMurdo Sound are indicated in Figure 6. At each location these samples included a large oriented block excavated to $0.6 \mathrm{~m}$ depth with a chain saw and an oriented core extending the full thickness of the ice sheet. (Absolute orientation of samples was possible in fast ice, a condition that does not apply to floes drifting in the Weddell Sea. In the case of pack ice the core from any particular floe could be

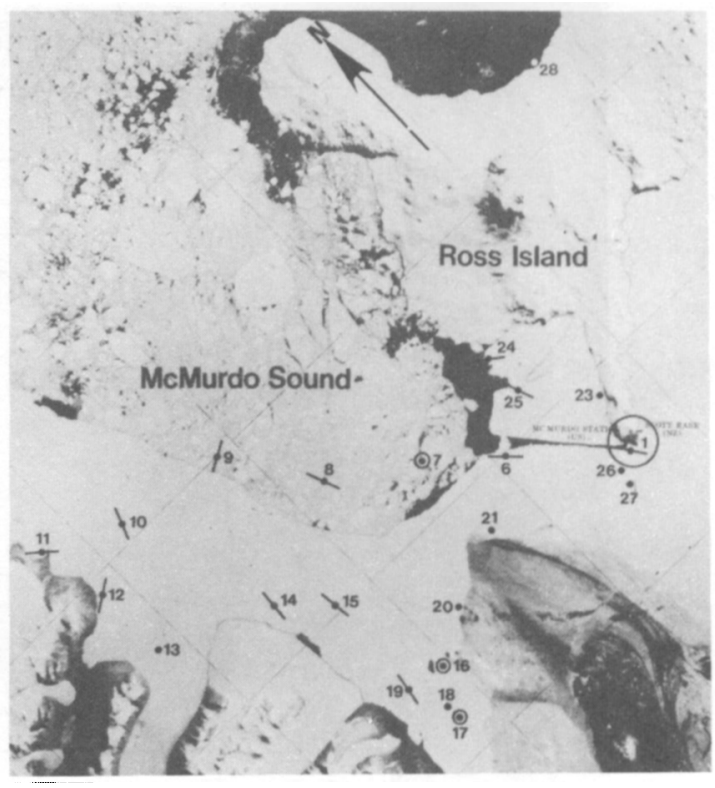

Fig.6. Satellite-image map of McMurdo Sound showing locations of sea-ice sampling sites. Circled area showing the location of site 1 also includes sites $2,3,4,5$, and 22 . At several of the sites the direction of preferred c-axis alignment is indicated by a line passing through the solid circle marking the site. At sites marked with a solid circle only, the c-axis orientation has yet to be determined. Sites showing random alignments of c-axes are marked with open circles. Note that sites 7,8 , and 9 were actually located on fast ice, not on drifting pack ice as indicated on this particular satellite-image map prepared from ERTS-1 data obtained on 13 January 1973. The lengths of the north-south grid lines are 15 nautical miles.

oriented only in a relative sense.) A second core was drilled and processed on site for salinity measurements.

Internal structure of ice

Preliminary investigations of the crystal structure of samples from 28 locations revealed widespread formation of congelation ice but only minimal amounts of frazil ice, limited generally to the upper layers of the sea-ice sheet. Frazil ice of the type that characterizes much of the pack ice in the weddell Sea was not detected in McMurdo Sound and the virtual absence of such ice in McMurdo Sound can probably be attributed to its origin as fast ice and to the lack of large leads and polynyas. However, the formation of a sub-ice platelet layer with individual plates measuring up to several centimeters in length was observed at the majority of sampling sites. This phenomenon was also noted by Paige (1966). At one location, the sub-ice platelet layer was observed extending several tens of centimeters below the bottom of the sea ice.

Petrographic studies (see Figs.7 and 8 for typical textures and fabrics) revealed crystalline structures and $c$-axis orientations that exhibited much in common with fast ice of the Arctic coast of Alaska as reported by Weeks and Gow (1978, 1980). Strong to moderate $c$-axis alignments were observed at about $60 \%$ of the sampling sites in McMurdo Sound. As was observed in the Arctic, these alignments appear linked to the measured and/or inferred direction of the current at the ice-water interface. The current data are still being analyzed, but a consideration of coastal outlines and the current data of other workers show that our alignments are compatible with current control at the ice-water interface. 


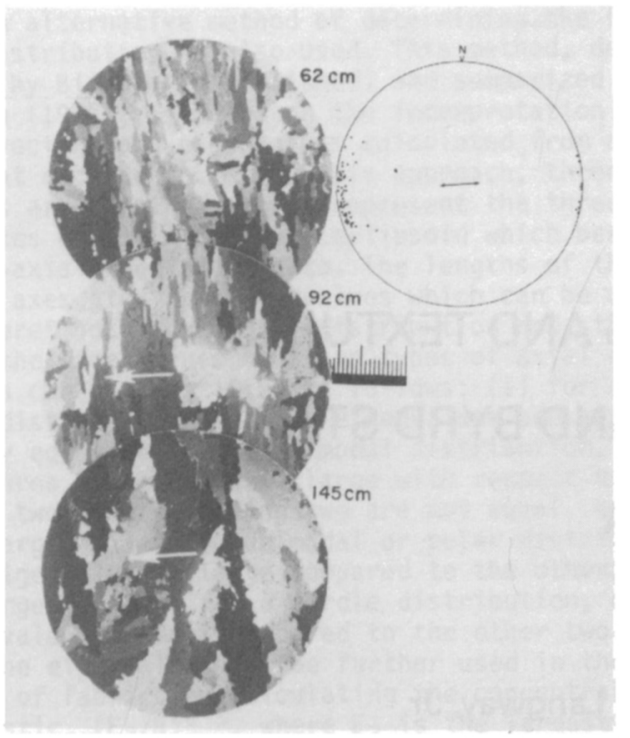

Fig.7. Crystalline textures in thin sections of sea ice from site 2, McMurdo Sound. All three sections exhibit a very strong east-west alignment of the crystallographic c-axes. Smallest subdivision of scale beside section from $0.92 \mathrm{~m}$ measures $1 \mathrm{~mm}$.

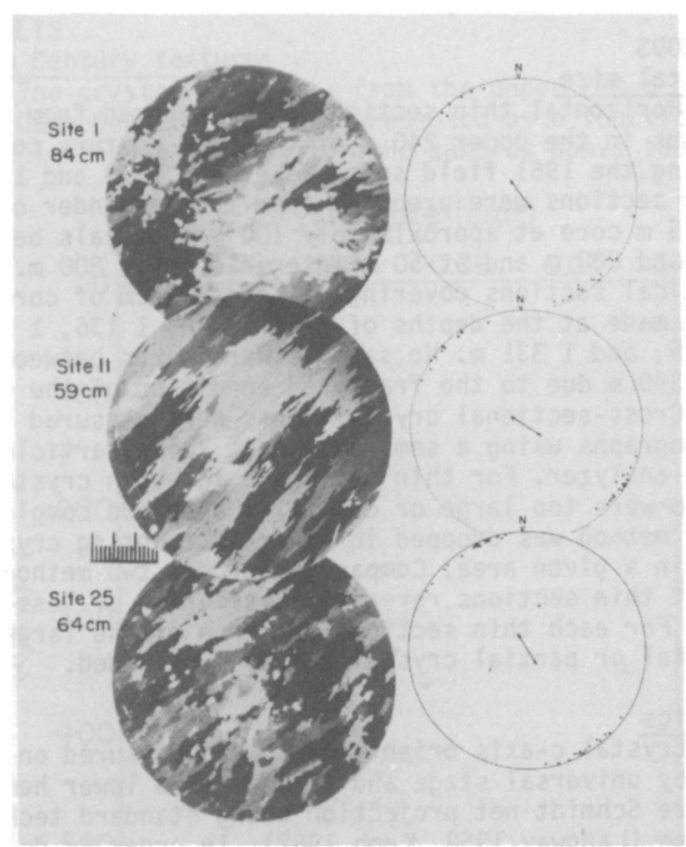

Fig.8. Crystalline textures and c-axis fabric plots of sea ice from sites 1,11 , and 25 in McMurdo Sound. The c-axis alignments at all three locations are compatible with the inferred current directions based on coastal configurations and existing current data. Photographic scale subdivisions measure $1 \mathrm{~mm}$.

\section{Salinity measurements}

Salinity profiles measured at 26 first-year ice sites yielded an average salinity of $6 \%$. The ice averaged $2 \mathrm{~m}$ in thickness. According to data assembled by Cox and Weeks (1973) cold ice of comparable age and thickness in the Arctic has an average salin$i$ ty of between 4 and $5 \%$. Ice from the one multiyear site also produced a relatively high average salinity of $4.2 \%$. According to the salinity-ice thickness relationship obtained by Cox and Weeks (1973) multi-year ice of comparable thickness $(5 \mathrm{~m})$ in the Arctic would yield an average salinity of only about $2 \%$. Higher average salinities measured in McMurdo sea ice are attributed to faster freezing rates.

\section{CONCLUSIONS}

Observations of the internal structure of 66 separate ice floes in the Weddell Sea reveal the existence of frazil ice in amounts that far exceed those previously reported in sea ice of comparable age, thermal history, and thickness in the Arctic. It is estimated that as much as $50 \%$ of the total ice production in the Weddell Sea is generated as frazil. Such widespread formation of frazil ice leads to exceptional ice-floe thicknesses, approaching $5 \mathrm{~m}$ of ice growth in 2 a in a number of floes examined. Weddell Sea pack ice is also found to be appreciably more saline than sea ice of comparable age and thickness in the Arctic. This increased average salinity of Weddell Sea pack is attributed mainly to the low top-surface summer melt that impedes loss of brine by flushing-out processes, and partly to the presence of frazil ice that is better suited structurally to the entrapment and retention of brine than is congelation ice.

Fast ice in McMurdo Sound is composed almost entirely of congelation ice exhibiting crystalline textures and c-axis alignment patterns that closely parallel those observed in Arctic fast ice. However, salinity profiles measured at 26 separate sites in McMurdo Sound also indicate that this ice is appreciably more saline than its Arctic counterpart.

\section{REFERENCES}

Ackley S F 1979 Mass-balance aspects of Wedde11 Sea pack ice. Journal of Glaciology 24(90): 391-405

Ackley S F 1981 Sea-ice atmosphere interactions in the Weddell Sea using drifting buoys. International Association of Hydrological Sciences Publication 131 (Symposium at Canberra 1979 - Sea lever, ice and climatic change): 177-191

Ackley S F, Gow A J, Buck K R, Golden K M 1980 Sea ice studies in the Weddell Sea aboard USCGC Polar Sea. Antarctic Joumal of the United States 15(5): 84-86

Cox G F N, Weeks WF 1973 Salinity variations in sea ice. CRREL Research Report 310

Gow A J, Weeks W F, Govoni J W, Ackley S $F$ In press Physical and structural characteristics of sea ice in McMurdo Sound. Antarctic Journal of the United States

Paige R A 1966 Crystallographic studies of sea ice in McMurdo Sound, Antarctica. US Naval Civit Engineering Laboratory. Technical Report R494 Weeks W F, Gow A J 1978 Preferred crystal orientations in the fast ice along the margins of the Arctic Ocean. Journal of Geophysical Research 83(C10): 5105-5121

Weeks W F, Gow A J 1980 Crystal alignments in the fast ice of Arctic Alaska. Journal of Geophysical Research 85(C2): 1137-1146 